\title{
Occupational exposures and lung cancer in $\mathrm{New}$ Caledonia
}

\author{
G Menvielle, D Luce, J Févotte, I Bugel, C Salomon, P Goldberg, M-A Billon-Galland, \\ M Goldberg
}

Occup Environ Med 2003;60:584-589

See end of article for authors' affiliations

Correspondence to:

Dr D Luce, INSERM Unité

88, Hôpital National de

Saint-Maurice, 14 rue du

Val d'Osne, 94415

Saint-Maurice Cedex

France;

Daniele.Luce@

st-maurice.inserm.fr

Accepted 23 September 2002

\begin{abstract}
Aims: To study the associations between occupational exposures and the risk of lung cancer in New Caledonia.

Methods: All cases diagnosed between January 1993 and December 1995 (228 lung cancers) and 305 population controls were included. Detailed information on lifetime job history, smoking, and other potential risk factors was collected by interview. Occupational exposures were assessed from the questionnaires by an industrial hygienist, without knowledge of case-control status.

Results: No significant association was found with exposures related to nickel mining and refining, the main industrial activity in the territory. Among men, an excess risk of lung cancer was found for bus and truck drivers. Increased risks were also observed in men with the highest level of cumulative exposure to cleaning products and inorganic fertilisers. Exposure to field dust was associated with lung cancer risk in both sexes, and risk increased with cumulative exposure level. In some areas tremolite asbestos derived from local outcroppings was used as a whitewash. The association between exposure to field dust and lung cancer was limited to men and women exposed to this whitewash - that is, living in areas where the soil may contain tremolite.

Conclusion: This study shows several associations between occupational exposures and lung cancer. The findings suggest that exposure to tremolite fibres from cultivated fields may increase the risk of lung cancer in New Caledonia.
\end{abstract}

$\mathrm{N}$ ew Caledonia is a French territory located in the South Pacific. Its population of 200000 inhabitants includes approximately $45 \%$ Melanesians (Kanaks), 35\% persons of European origin, and 20\% other ethnic groups, principally Polynesians. Nickel mining and refining is the main industrial activity.

In the 1980s an increased and increasing incidence of lung cancer, and an especially high incidence of pleural mesothelioma was observed in New Caledonia. ${ }^{12}$ A case-control study was then undertaken, to assess the respective roles of environmental, occupational, and lifestyle factors on the incidence of respiratory cancers in this territory. Initial results showed the existence of environmental exposure to tremolite asbestos by the application of a whitewash, locally called "pö". Exposure to pö strongly increased the risk of mesothelioma among men and women, as well as the risk of lung cancer among women. ${ }^{3}$ The study of dietary factors did not show any strong associations with lung cancer risk, but did suggest that consumption of green leafy vegetables (a traditional food of the South Pacific) may play a protective role. ${ }^{4}$ The role of occupational exposures has not been investigated until now except for dust from mines, building sites, roads, and fields. The objective of this work was therefore to study the associations between occupations, industries, and occupational exposures to different substances and the risk of lung cancer.

\section{Main messages}

- Among men, motor vehicle drivers and cleaners exposed to household cleaning products show an increased risk of lung cancer.

- Exposure to field dust is related to lung cancer in both sexes. The association is limited to men and women living in areas where the soil may contain tremolite asbestos.

\section{SUBJECTS AND METHODS}

The subjects and methods have been described previously. ${ }^{3}$ Briefly, this is a population based case-control study. We did not include subjects who had lived in the territory for less than five years or who were younger than 18 years of age. The cases were identified from the New Caledonia Cancer Registry. All primary lung cancers (code 162 of the International Classification of Diseases, 9th revision) diagnosed between 1 January 1993 and 31 December 1995 were included in the study. Of the 230 eligible cases, two refused to participate. The population controls were randomly selected from the electoral rolls, with frequency matching by sex and age. Of the 320 eligible controls whom we contacted, 305 agreed to participate.

Study subjects were interviewed in person by a specially trained interviewer. The questionnaire asked for information about social and demographic characteristics, ethnicity, smoking and drinking (alcohol), dietary habits, residential history (in particular, past or present exposure to pö), and job history (listing of all jobs held by the subject, description of the tasks performed and products used). The job history section of the questionnaire was adapted to New Caledonia in collaboration with local occupational physicians and labour department inspectors. In addition, we developed specific questionnaires related to particular tasks or common occupations (farming, gardening or truck farming, woodworking, mechanics, plumbing, shipyards, and construction work). These allowed the interviewer to ask more relevant questions.

\section{Policy implications}

- The possibility that exposure to tremolite fibres from cultivated fields may increase the risk of lung cancer in New Caledonia should be further investigated. 
When the subject had died (39 patients with lung cancer) or was too ill to be questioned ( 19 cases and two controls), we interviewed a next-of-kin with a shorter version of the questionnaire. Job history could be collected more succinctly with this shorter questionnaire, which did not include any of the job specific sections. This shorter questionnaire was also used for in-person interviews of some subjects who could not respond to the complete questionnaire, principally for health reasons ( 34 cases and five controls).

Two cases whose job histories were unknown were excluded from the analysis, which thus considers 226 cases and 305 controls.

Occupations were coded according to the International Labor Organization's International Standard Classification of Occupations (ISCO) ${ }^{5}$ and industries (branch of activity) according to the United Nations International Standard Industrial Classification (ISIC).

Occupational exposures were assessed for each subject by an expert in industrial hygiene (JF) from the detailed job description. This coding was performed without knowledge of the subjects' case or control status. For each exposed job, the expert coded the environmental concentration of each substance (on a scale of 1 to 10), the frequency of exposure, or proportion of working time during which the person was exposed (from 1 (less than 10\%) to 10 (more than 90\%)), and the probability of exposure (from 1 to 3 : possible, probable, or certain exposure). The analysis also included the dates that exposure began and ended. The exposures considered cover the largest possible range of products, in very diverse presentations: pure products, chemical families, complex mixtures, processes, or families of use. The list of exposures contained approximately 300 items and was similar to that used by Siemiatycki in a case-control study in Montreal, ${ }^{7}$ with minor modifications to reflect the local conditions.

We used unconditional logistic regression to estimate the adjusted odds ratios (OR) and their 95\% confidence intervals (CI). All analyses used SAS software, version 8.0. Separate analyses were performed for men and women, with adjustment for age (younger than 55 years, 56-65 years, and older than 65 years) and smoking (in pack-years, coded in four classes for men (less than 20,20-40,40-60, and more than 60) and three classes for women (non-smoker, less than 20, and more than 20)). The model for men also included ethnicity (Melanesian/other). The odds ratios for women were also adjusted for exposure to pö, in view of the results from our first analysis of these data. ${ }^{3}$ A 15 year induction latency period was taken into account by lagging exposures for 15 years. The results obtained with the 15 year latency period differ little from those obtained without considering a latency period and are not presented in this article.

Job title analysis was performed using the first two digits of the ISCO code. All jobs held by at least three cases were examined. When a sufficient number of subjects were exposed, a more detailed analysis was conducted using three or five digits. A dichotomous exposure variable (ever/never employed in that job) and job duration were used. Similar analyses were performed for the branches of activity. Results are presented when an increased odds ratio was observed.

To quantify exposure, we used two variables: ever/never, and level of cumulative exposure. For each subject and each exposure, the cumulative exposure level was computed by summing over the total work history the job specific products of concentration, frequency, probability, and duration. The cumulative exposure level was then categorised in four classes: not exposed, and low, medium, and high exposure, based on the distribution of exposure among controls. To isolate people exposed to the lowest level we used the 25th centile as cut point. To study those exposed to the highest level, we used the 90th centile for men and the 75th centile for women (because of the smaller sample size). When a dose-response relation was suggested, we performed trend tests, by
Table 1 Lung cancer in women; adjusted odds ratios* for selected occupations and industries 169 controls and 51 cases)

\begin{tabular}{|c|c|c|c|}
\hline & \multirow[b]{2}{*}{ OR $(95 \% \mathrm{Cl})$} & \multicolumn{2}{|c|}{ Exposed } \\
\hline & & Cases & Controls \\
\hline \multicolumn{4}{|l|}{$\begin{array}{l}\text { Farm workers } \\
\text { (ISCO code: } 62105 \text { ) }\end{array}$} \\
\hline Ever employed & $1.9(0.7$ to 4.9$)$ & 26 & 20 \\
\hline Less than 25 years & $1.0(0.3$ to 3.7$)$ & 6 & 9 \\
\hline 25 years or longer & $2.7(0.9$ to 8.0$)$ & 20 & 11 \\
\hline \multicolumn{4}{|c|}{$\begin{array}{l}\text { Agricultural production and animal husbandry } \\
\text { (ISIC code: } 1110 \text { ) }\end{array}$} \\
\hline Ever employed & $1.6(0.6$ to 4.0$)$ & 27 & 24 \\
\hline Less than 25 years & $0.6(0.2$ to 2.2$)$ & 5 & 12 \\
\hline 25 years or longer & 2.8 (1.0 to 8.1$)$ & 22 & 12 \\
\hline
\end{tabular}

introducing the exposure index into the models as a quantitative variable, its value defined as the median of each category. Given the large number of exposures being analysed, we selected results for presentation on the basis of three criteria: known or suspected lung carcinogens (asbestos, arsenic compounds, nickel compounds, silica, diesel exhaust gas, polycyclic aromatic hydrocarbons, inorganic acids, pesticides); the odds ratio for the dichotomous exposure variables (ever/ never) is above 1 with a lower confidence interval limit above 0.7 ; and there was some indication of a dose-response relation with cumulative exposure.

\section{RESULTS}

\section{Lung cancer in women}

Table 1 summarises the results of the analysis by job titles. The odds ratio for women farm workers was increased but not significantly. The odds ratios increased with the duration of exposure, and that for women who had been employed for more than 25 years was on the borderline of significance. The analysis by industry confirms these results: the odds ratio associated with more than 25 years of work in agricultural production was significantly greater than 1 .

Exposure to straw, hay, and grass dust and to field dust significantly increased the risk of lung cancer (table 2). Analysis of the dichotomous variables showed non-significant odds ratios around 2. Nonetheless, the odds ratios increased with the level of cumulative exposure. The odds ratios associated

Table 2 Lung cancer in women; adjusted odds ratios* for selected occupational exposures 169 controls and 51 cases)

\begin{tabular}{|c|c|c|c|}
\hline \multirow[b]{2}{*}{ Exposure index } & \multirow[b]{2}{*}{ OR $(95 \% \mathrm{Cl})$} & \multicolumn{2}{|c|}{ Exposed } \\
\hline & & Cases & Controls \\
\hline \multicolumn{4}{|c|}{ Straw, hay, or grass dust } \\
\hline Ever exposed & 2.0 (0.8 to 5.0$)$ & 30 & 24 \\
\hline \multicolumn{4}{|l|}{ Cumulative exposure $†$} \\
\hline$<25$ th centile & $1.3(0.3$ to 5.8$)$ & 5 & 6 \\
\hline 25 th- 75 th centiles & $2.0(0.7$ to 6.0$)$ & 16 & 12 \\
\hline$>75$ th centile & $2.9(0.8$ to 11.2$)$ & 9 & 6 \\
\hline \multicolumn{4}{|l|}{ Field dust } \\
\hline Ever exposed & $2.1(0.8$ to 5.1$)$ & 30 & 24 \\
\hline \multicolumn{4}{|l|}{ Cumulative exposure $†$} \\
\hline$<25$ th centile & $1.0(0.2$ to 4.8$)$ & 4 & 6 \\
\hline 25 th-75th centiles & $1.8(0.6$ to 5.5$)$ & 14 & 12 \\
\hline$>75$ th centile & 4.0 (1.1 to 15.0$)$ & 12 & 6 \\
\hline
\end{tabular}

*Odds ratios adjusted for age, smoking, and pö exposure. †Centiles based on the distribution among controls. Cut points for 25th and 90th centiles, respectively: straw, hay, or grass dust: 57,123 ; field dust: 45,115 . 
Table 3 Lung cancer in women; joint effects of exposure to field dust and to pö 169 controls and 51 cases)

\begin{tabular}{|c|c|c|c|c|}
\hline \multirow[b]{2}{*}{ Exposure to field dust } & \multicolumn{2}{|c|}{ Never exposed to pö } & \multicolumn{2}{|c|}{ Ever exposed to pö } \\
\hline & Cases/controls & OR $(95 \% \mathrm{Cl})$ & Cases/controls & OR $(95 \% \mathrm{Cl})$ \\
\hline Never & $17 / 38$ & 1.0 & $4 / 7$ & 1.0 \\
\hline Ever & $13 / 15$ & $1.7(0.6$ to 5.0$)$ & $17 / 9$ & 3.3 (2.4 to 4.5 ) \\
\hline
\end{tabular}

with a cumulative exposure above the 75 th centile were significant or borderline significant. Moreover, these two exposures were very closely associated, and their effects cannot be distinguished: 52 of 54 exposed women were subjected to both.

Two thirds of the exposed women were Melanesian and practised tribal agriculture. The soil contains tremolite in some areas, in particular, those where the women exposed to pö lived. Exposure to field dust may thus constitute additional exposure to tremolite. Moreover, the odds ratio associated with exposure to field dust was 3.3 in women exposed to pö and 1.7 in those not exposed to it (table 3 ).

\section{Lung cancer in men}

Table 4 summarises the results of the analysis by occupation and industry. Although based on small numbers, a significant association was found for forestry workers and machine fitters and assemblers. The risk of lung cancer was also significantly associated with more than five years of dock work. The odds ratio for building caretakers and cleaners was high, but not significant, as was that for household workers. Nonetheless, the duration of exposure was substantially lower among controls than cases, and no control subject worked as a building caretaker for more than five years. Increased but nonsignificant odds ratios were found among farm workers and in the agricultural production industry, and the risk increased with duration of exposure. Finally, an odds ratio significantly greater than 1 was observed among transport equipment operators who had been working for more than 20 years. A more detailed analysis revealed that odds ratios were significantly increased among bus and truck drivers and increased with duration of exposure.

Table 5 summarises the principal results for specific agents. The analysis with the ever/never variable found no significant associations, even though some odds ratios were high. The use of the cumulative exposure level showed that several exposures were associated with an increased risk.

Among known or suspected risk factors for lung cancer, we found no association and no indication of a dose-response relation for exposure to asbestos, arsenic compounds, organic acids, nickel compounds, polycyclic aromatic hydrocarbons (PAH), diesel exhaust gas, or organic or inorganic pesticides. Silica exposure was associated with a high odds ratio, but only for the lowest exposure category.

Significant odds ratios were observed for exposure at the highest level of cumulative exposure to inorganic fertiliser (OR 9.3, 95\% CI 1.5 to 55.6), field dust (OR 2.6, 95\% CI 1.0 to 7.3 ), and household cleaning products (OR 15.1, 95\% CI 1.3 to 170). Dose-response relations with duration and cumulative exposure level were observed.

The odds ratios associated with natural gas combustion products and straw dust, while not significantly greater than l, increased with exposure level. A similar trend, albeit not significant and based on quite small numbers, was observed for exposure to plastic dust, natural fertilisers, and house dust.

\begin{tabular}{|c|c|c|c|c|}
\hline \multirow[b]{2}{*}{ Occupation } & \multirow[b]{2}{*}{ ISCO code } & \multirow[b]{2}{*}{ OR $(95 \% \mathrm{Cl})$} & \multicolumn{2}{|c|}{ Exposed } \\
\hline & & & Cases & Controls \\
\hline Forestry workers & $63 x x x$ & $15.8(1.5$ to 172$)$ & 5 & 1 \\
\hline Farm workers & 62105 & $1.3(0.8$ to 2.3$)$ & 70 & 86 \\
\hline Less than 25 years & & $1.2(0.7$ to 2.2$)$ & 39 & 56 \\
\hline 25 years and longer & & $1.5(0.7$ to 3.2$)$ & 31 & 30 \\
\hline Machinery fitters and machine assemblers & $841 x x$ & $7.1(1.1$ to 48.0$)$ & 6 & 2 \\
\hline Building caretakers, charworkers, and cleaners & $55 x x x$ & $3.7(0.8$ to 17.4$)$ & 7 & 3 \\
\hline Less than 5 years & & $0.7(0.1$ to 5.6$)$ & 2 & 3 \\
\hline 5 years or longer & & $t$ & 5 & 0 \\
\hline Dockers & 97120 & $1.1(0.5$ to 2.3$)$ & 22 & 26 \\
\hline Less than 5 years & & 0.5 (0.2 to 1.4$)$ & 10 & 20 \\
\hline 5 years or longer & & $3.3(1.0$ to 10.7$)$ & 12 & 6 \\
\hline Transportation equipment operators & $98 x x x$ & $1.0(0.5$ to 2.0$)$ & 23 & 33 \\
\hline Less than 20 years & & 0.8 (0.4 to 1.6$)$ & 18 & 30 \\
\hline 20 years or longer & & $5.8(1.1$ to 30.7$)$ & 5 & 3 \\
\hline Motor bus and lorry and van drivers & 98540 and & $2.7(1.1$ to 7.0$)$ & 13 & 15 \\
\hline Less than 15 years & 98550 & $2.1(0.7$ to 22.1$)$ & 8 & 11 \\
\hline 15 years or longer & & $4.7(1.0$ to 22.1$)$ & 5 & 4 \\
\hline Industry & ISIC code & & & \\
\hline Household service workers & 9530 & $2.4(0.6$ to 10.0$)$ & 6 & 5 \\
\hline Less than 5 years & & $0.7(0.1$ to 5.3$)$ & 2 & 4 \\
\hline 5 years or longer & & $11.7(1.0$ to 141$)$ & 4 & 1 \\
\hline Agricultural production and animal husbandry & 1110 & $1.1(0.7$ to 1.8$)$ & 93 & 115 \\
\hline Less than 30 years & & $0.9(0.6$ to 1.6$)$ & 54 & 82 \\
\hline 30 years or longer & & $1.7(0.8$ to 3.4$)$ & 39 & 33 \\
\hline
\end{tabular}


Table 5 Lung cancer in men; adjusted odds ratios $†$ for selected occupational exposures (236 controls and 175 cases)

\begin{tabular}{|c|c|c|c|c|c|c|}
\hline \multirow[b]{3}{*}{ Exposure } & \multicolumn{2}{|c|}{ Exposed } & \multicolumn{4}{|l|}{ Odds ratio } \\
\hline & \multirow[b]{2}{*}{ Cases } & \multirow[b]{2}{*}{ Controls } & \multirow[b]{2}{*}{ Ever/never } & \multicolumn{3}{|c|}{ Cumulative exposure centilesł } \\
\hline & & & & $<25$ & $25-90$ & $>90$ \\
\hline Asbestos & 80 & 113 & $0.8(0.5$ to 1.2$)$ & 0.5 & 0.9 & 0.8 \\
\hline Arsenic compounds & 16 & 26 & $0.7(0.3$ to 1.5$)$ & 0.8 & 0.6 & 0.8 \\
\hline Inorganic acid solutions & 20 & 30 & $0.9(0.4$ to 1.8$)$ & 1.3 & 0.7 & ๆ \\
\hline Metal coatings & 21 & 23 & $1.4(0.7$ to 3.0$)$ & 2.0 & 1.2 & 1.2 \\
\hline Welding alloy dust & 8 & 7 & $2.3(0.7$ to 8.0$)$ & 2.0 & 2.5 & 2.0 \\
\hline Plastic dust & 3 & 4 & $1.3(0.2$ to 7.7$)$ & ๆ & 1.0 & 5.0 \\
\hline Construction site dust & 53 & 61 & $1.1(0.7$ to 1.9$)$ & 1.5 & 1.1 & 0.5 \\
\hline Natural gas combustion products & 6 & 11 & $0.8(0.2$ to 2.7$)$ & 0.6 & 0.2 & 2.4 \\
\hline Tolvene & 64 & 84 & $1.2(0.7$ to 1.9$)$ & 1.6 & 1.0 & 1.2 \\
\hline Xylene & 64 & 83 & $1.2(0.7$ to 1.9$)$ & 1.8 & 1.1 & 1.2 \\
\hline Diesel engine emissions & 88 & 130 & $0.8(0.5$ to 1.2$)$ & 0.9 & 0.7 & 0.7 \\
\hline $\mathrm{PAH}$ from any source & 124 & 174 & $0.8(0.5$ to 1.4$)$ & 1.0 & 0.8 & 0.6 \\
\hline $\mathrm{MAH}$ & 94 & 128 & $1.2(0.7$ to 1.9$)$ & 1.7 & 1.1 & 0.4 \\
\hline Diesel oil & 65 & 89 & $1.1(0.7$ to 1.8$)$ & 1.2 & 1.1 & 0.5 \\
\hline Copra & 12 & 10 & $1.9(0.7$ to 5.7$)$ & $6.7^{*}$ & 1.0 & 2.3 \\
\hline Inorganic fertilisers & 11 & 16 & $1.2(0.5$ to 3.3$)$ & 1.1 & 0.4 & $9.3^{* *} \dagger \dagger$ \\
\hline Natural fertilisers & 3 & 7 & $1.1(0.2$ to 5.6$)$ & ף & 0.6 & 12.7 \\
\hline Organic pesticides & 25 & 40 & $0.7(0.4$ to 1.4$)$ & 0.9 & 0.6 & 1.2 \\
\hline Inorganic pesticides & 17 & 28 & $0.6(0.3$ to 1.3$)$ & 0.1 & 0.9 & 0.8 \\
\hline Field dust & 99 & 117 & $1.1(0.7$ to 1.9$)$ & 0.7 & 1.1 & $2.6 * \dagger \dagger$ \\
\hline Hay, grass, or straw dust & 123 & 99 & $0.9(0.6$ to 1.6$)$ & 0.6 & 1.0 & 1.7 \\
\hline Refractory brick dust & 8 & 6 & $2.8(0.7$ to 10.6$)$ & 6.3 & 2.6 & 1.0 \\
\hline Silica & 30 & 46 & $0.9(0.5$ to 1.6$)$ & 2.2 & 0.7 & 0.3 \\
\hline Iron matte & 32 & 38 & $1.3(0.7$ to 2.5$)$ & 1.2 & 1.5 & ๆ \\
\hline Iron and nickel oxides & 26 & 38 & $0.9(0.5$ to 1.8$)$ & 0.7 & 1.0 & 1.3 \\
\hline Nickel compounds & 24 & 35 & $1.3(0.7$ to 2.6$)$ & 0.5 & 1.8 & ๆ \\
\hline House dust & 6 & 4 & $2.7(0.6$ to 12.2$)$ & 1.6 & $\S$ & 2.8 \\
\hline Cleaning products & 7 & 10 & $1.5(0.5$ to 5.0$)$ & ๆ & 0.4 & $15.1 * * \dagger \dagger$ \\
\hline \multicolumn{7}{|c|}{ 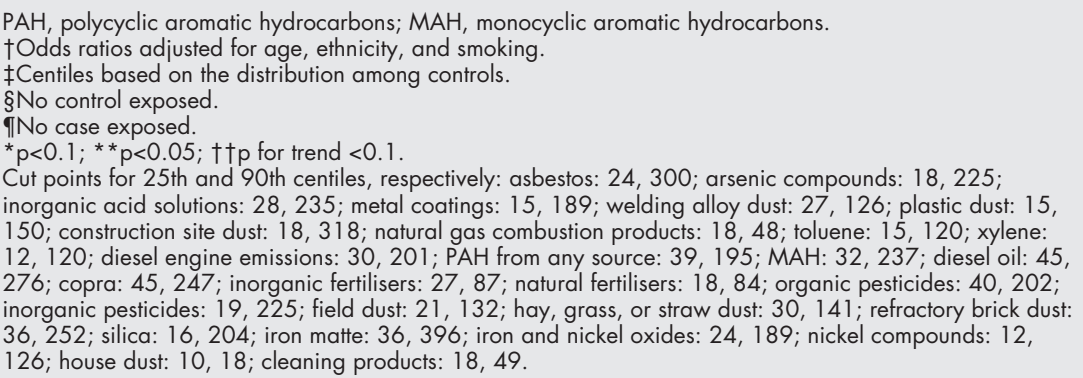 } \\
\hline
\end{tabular}

Increased but non-significant odds ratios were observed for lower cumulative levels of exposure to copra, to monocyclic aromatic hydrocarbons, and to refractory brick dust, but the odds ratios then diminished as the exposure level increased.

For the other exposures (metal coatings, welding alloy dust, construction site dust, diesel oil, iron matte, toluene, and xylene), high but non-significant odds ratios were observed with the exposed/not exposed variable, and there was no indication of any dose-response relation.

Generally, lung cancer was not associated with any of the exposures related to nickel industry: nickel compounds, iron and nickel oxides, iron matte, refractory bricks, or silica.

The preceding results reveal two major exposure groups: agriculture, with copra, field dust, straw dust, natural and inorganic fertilisers, and pesticides; and household cleaning, with exposure to cleaning products and house dust.

Like the women, the men exposed to pö lived in regions where the soil contained tremolite, and the field dust to which they were exposed was more likely to contain this asbestos. Among men exposed to pö, the odds ratio associated with a level of cumulative exposure to field dust above the 90th centile was 5.7 compared with 2.0 among those not exposed (table 6).

\section{DISCUSSION}

The interviewers were experienced and received specific training for this project. They knew, however, the case/control status of the persons they were questioning, which could have

Table 6 Lung cancer in men; joint effects of exposure to field dust and to pö (236 controls and 175 cases)

\begin{tabular}{llllll}
\hline & \multicolumn{2}{l}{ Never exposed to pö } & & \multicolumn{2}{l}{ Ever exposed to pö } \\
\cline { 2 - 3 } Exposure to field dust & Cases/controls & $95 \% \mathrm{Cl}$ & & Cases/controls & $95 \% \mathrm{Cl}$ \\
\hline Never & $70 / 99$ & 1.0 & $6 / 20$ & 1.0 \\
<90th centile & $61 / 66$ & $0.9(0.5$ to 1.7$)$ & & $22 / 38$ & 1.9 (0.6 to 6.3) \\
>90th centile & $9 / 5$ & $2.0(0.5$ to 7.8$)$ & & $7 / 8$ & $5.7(1.1$ to 29.7$)$ \\
\hline
\end{tabular}

Odds ratios adjusted for age, tobacco consumption, and ethnicity. 
led to differential misclassification. A differential recall bias may also have occurred, with case subjects more likely than healthy controls to remember past exposures. Nonetheless, several factors suggest that the quality of the job related data we collected was comparable for cases and controls. First, the mean duration of the interviews was similar for cases (109 minutes) and controls (106 minutes). In addition, the interviewer assessed the quality of the interview at the end of the questionnaire (good, average, poor) and rated them as good for $75 \%$ of the cases and $85 \%$ of the controls. Finally, the average number of jobs reported by cases (2.8 jobs) and controls (3.1 jobs) was equivalent.

We used shorter questionnaires in some cases. These questionnaires, which were most often used when it was necessary to interview a next-of-kin, provided less precise information than the complete questionnaires. To know to what extent this procedure might have biased the results, we re-analysed the data with the exposed/not exposed variable and only the complete questionnaires. Consideration of the shorter questionnaires had very little effect on the results; this finding suggests that if this bias exists, it is not very important.

Occupational exposures were assessed case by case, from a questionnaire that described the jobs in detail. This method should limit misclassification of exposure. Moreover, since exposures were assessed without knowledge of case-control status, potential misclassification would be non-differential and would thus tend to underestimate associations.

The principal possible confounding factors were examined and taken into account when necessary. The relatively low number of subjects nonetheless resulted in fairly crude coding for some variables, and a residual confounding effect cannot be excluded.

The small number of subjects hampered some analyses, especially for women. To increase statistical power, we thus considered pooling men and women and adjusting for sex. However, because the occupational exposures varied strongly by sex and the confounding factors were different (pö exposure for women only), it seemed preferable to perform separate analyses. An additional problem related to the relatively low number of subjects was the impossibility of systematic separate analyses by histological type of lung cancer.

Because of the number of comparisons, we cannot exclude the possibility that some associations were caused by chance. Multiple comparisons are a complex problem that also depends on the validity and the plausibility of the hypotheses tested and on the aim of the study. ${ }^{8}$ We paid special attention to the exposures for which results from different analyses were consistent: associations observed with both binary indicators and categorical variables, as well as consistency with analyses by occupation or industry. Thus the results we focused on are not likely to be caused by chance.

Free silica is an established carcinogen, and many studies have found significantly higher risks of lung cancer for individuals exposed to it, a risk that increases with the duration of exposure. ${ }^{7-11}$ In our study, high odds ratios were observed only for low exposure levels.

Similarly, asbestos, also a known pulmonary carcinogen, ${ }^{12}$ was not associated with lung cancer in this study. However, the strongest associations have been observed in cohort studies among highly exposed individuals. Population based studies generally show moderate odds ratios, and sometimes-as here-no association at all.

No significant association was observed for exposures related to working with nickel. Similarly, the first studies in New Caledonia of nickel mining and refining company employees did not find an increased risk of lung cancer, probably because exposure levels were lower than those observed in positive studies in other countries. ${ }^{1}$

In this study, the analysis by occupations reveals an excess risk of lung cancer among motor vehicle drivers, particularly bus and truck drivers. This result has been found in numerous studies, among drivers generally, ${ }^{13}$ in the transportation industry, ${ }^{11}$ among men whose jobs require substantial driving, ${ }^{15}$ and among truckers. ${ }^{16}$ Exposure to PAH and to diesel fumes are often cited as explanations for the high risks observed in drivers. In our study, no significant association was found between exposure to diesel fumes or PAH and subsequent lung cancer.

Exposure to household cleaning products was strongly linked to lung cancer in our study. Moreover we found an odds ratio significantly greater than 1 among building caretakers and cleaning company employees, as well as an odds ratio greater than 1, but not significantly so, among domestic workers.

Very few studies have examined exposure to household cleaning products. This exposure was considered in a large case-control study in Canada, which looked at approximately 20 cancer sites and 293 occupational exposures. ${ }^{7}$ No association with lung cancer was observed.

High odds ratios have been found for occupations related to cleaning in several studies, sometimes significant, ${ }^{11}{ }^{17}$ sometimes not. ${ }^{14}{ }^{16}$ Results for branches of economic activity related to cleaning are available in various studies, but they are difficult to compare: cleaners are often pooled with other service occupations. High odds ratios have nonetheless been observed for cleaning service employees, ${ }^{16}{ }^{17}$ cleaners, hairdressers, and bartenders, ${ }^{14}$ the laundry and cleaning industry, ${ }^{16}$ and service occupations as a whole. ${ }^{11}$ Our results point in the same direction as those previously reported.

This association between exposure to household cleaning products and lung cancer was not found among the women in our study. It is improbable that the results observed in men were caused by chance. Exposure to household cleaning products has been significantly associated with the risk of lung cancer in several analyses, and odds ratios greater than 1 have been associated with cleaning trades and the cleaning industry. Products used by men and women may differ, because men work principally in the cleaning industry whereas women work in private homes. It is also possible that the association with exposure to cleaning products is diluted in women, because they are all exposed in a non-occupational setting, for cleaning their own homes.

In our study, a high risk of lung cancer was observed in both men and women farm workers; the association was stronger in women. The association between farming and lung cancer is common in the literature. Significantly ${ }^{13}$ or nonsignificantly ${ }^{16}$ increased odds ratios have been found for occupations related to farming in several studies. ${ }^{9}$ Some authors suggest this may be an artefact related to the selection of controls from an urban area ${ }^{14}$; this is probably not the case in our study, where the distribution of controls by place of residence was similar to that of the general population.

Odds ratios significantly greater than 1 have been found for agriculture sector workers in several studies. ${ }^{11} 1416$ Nonetheless, the coding used varies from study to study, and farming is rarely considered alone. It is generally pooled together with fishing, hunting, animal husbandry, or silviculture.

Exposure to pesticides, which is sometimes associated with an increased risk of lung cancer, ${ }^{9}$ may explain the high odds ratios found in farm workers. Nonetheless, we found no association with pesticides in our study. On the other hand, a higher risk of cancer was found among men exposed to inorganic fertilisers - that is, nearly all the farm workers. The studies of the association between fertiliser exposure and lung cancer have generally been conducted in manufacturing plants, and most have found no association, ${ }^{18-20}$ although high odds ratios have been reported for some highly exposed individuals. $^{21}$

The first analyses of these data studied the association between exposure to field dust and lung cancer, without taking exposure levels into account. No association was observed in men, although non-significant high odds ratios were 
observed in women. ${ }^{3}$ In this analysis, an increased cumulative exposure to field dust was significantly associated with the risk of lung cancer in men and women. This exposure principally involved farm workers. In some regions, the soil contains tremolite, and exposure to these asbestos fibres from cultivated fields may explain the high odds ratios observed for field dust and for farming. The available data do not, however, allow us to distinguish the field dust exposures according to geographic zone. Nonetheless, this hypothesis is supported by the finding that exposure to field dust was particularly associated with lung cancer in individuals exposed to pö-that is, individuals residing in regions where the soil contains tremolite.

\section{Conclusion}

We identified three main occupational categories associated with an increased risk of lung cancer: among men only, cleaners with exposure to household cleaning products, and motor vehicle drivers for whom no particular exposure was clearly identified; among men and women, farm workers, with exposure to inorganic fertilisers and field dust.

Exposure to field dust was significantly associated with lung cancer in men and women. Because field dust may contain tremolite in some regions of New Caledonia, these results may thus reflect environmental exposure to asbestos. It should be possible in subsequent analyses to take the location of fields into account to try to distinguish with adequate precision the field dust likely to contain tremolite from other dust. This would make it possible to describe the exposure in better detail and to confirm or refute the hypotheses we have suggested here.

\section{Authors' affiliations}

G Menvielle, D Luce, I Bugel, C Salomon, P Goldberg, M Goldberg, Institut National de la Santé et de la Recherche Médicale, Unité 88, Saint-Maurice, France

J Févotte, Institut Universitaire de Médecine du Travail, Lyon, France M-A Billon-Galland, Laboratoire d'Etudes des Particules Inhalées, Paris, France

\section{REFERENCES}

1 Goldberg M, Goldberg P, Leclerc A, et al. A 10-year incidence survey of respiratory cancer and a case-control study within a cohort of nickel mining and refining workers in New Caledonia. Cancer Causes Control 1994;5:15-25.
2 Goldberg P, Goldberg M, Marne M, et al. Incidence of pleural mesothelioma in New Caledonia: a 10-year survey (1978-1987). Arch Environ Health 1991;46:306-9.

3 Luce D, Bugel I, Goldberg P, et al. Environmental exposure to tremolite and respiratory cancer in New Caledonia: a case-control study. Am J Epidemiol 2000;151:259-65.

4 Marchand JL, Luce D, Goldberg P, et al. Dietary factors and the risk of lung cancer in New Caledonia (South Pacific). Nutr Cancer 2002;42: 18-24.

5 International Labour Office. International standard classification of occupations. Geneva: BIT, 1968.

6 Statistical Office of the United Nations. International standard industrial classification of all economic activities. New York: United Nations, 1975.

7 Siemiatycki J, ed. Risk factors for cancer in the workplace. Boca Raton, FL: CRC Press, 1991.

8 Savitz DA, Olshan AF. Multiple comparisons and related issues in the interpretation of epidemiologic data. Am J Epidemiol 1995;142:904-8.

9 De Stefani E, Kogevinas M, Boffetta P, et al. Occupation and the risk of lung cancer in Uruguay. Scand J Work Environ Health 1996;22:346-52.

10 Steenland K, Stayner L. Silica, asbestos, man-made mineral fibers, and cancer. Cancer Causes Control 1997;8:491-503.

11 Bruske-Hohlfeld I, Mohner M, Pohlabeln H, et al. Occupational lung cancer risk for men in Germany: results from a pooled case-control study. Am J Epidemiol 2000;151:384-95.

12 Boffetta P, Saracci R. Occupational factors of lung cancer. In: Hirsch A, Goldberg M, Martin JP, Masse R, eds. Prevention of respiratory diseases. New York: Marcel Dekker, 1993:37-63.

13 Pezzotto SM, Poletto L. Occupation and histopathology of lung cancer: a case-control study in Rosario, Argentina. Am J Ind Med 1999; $36: 437-43$

14 Jockel KH, Ahrens W, Wichmann HE, et al. Occupational and environmental hazards associated with lung cancer. Int J Epidemiol 1992;21:202-13.

15 Bruske-Hohlfeld I, Mohner M, Ahrens W, et al. Lung cancer risk in male workers occupationally exposed to diesel motor emissions in Germany. Am J Ind Med 1999;36:405-14.

16 Matos EL, Vilensky M, Mirabelli D, et al. Occupational exposures and lung cancer in Buenos Aires, Argentina. J Occup Environ Med 2000;42:653-9.

17 Ronco G, Ciccone G, Mirabelli D, et al. Occupation and lung cancer in two industrialized areas of northern Italy. Int J Cancer 1988;41:354-8.

18 Fandrem SI, Kjuus $\mathrm{H}$, Andersen $\mathrm{A}$, et al. Incidence of cancer among workers in a Norwegian nitrate fertiliser plant. $\mathrm{Br} J$ Ind Med 1993;50:647-52.

19 Rafnsson V, Gunnarsdottir H. Mortality study of fertiliser manufacturers in Iceland. Br J Ind Med 1990;47:721-5.

20 Fraser $\mathbf{P}$, Chilvers $C$, Day $M$, et al. Further results from a census based mortality study of fertiliser manufacturers. Br J Ind Med 1989;46:38-42.

21 Bulbulyan MA, Jourenkova NJ, Boffetta P, et al. Mortality in a cohort of Russian fertilizer workers. Scand J Work Environ Health 1996;22: 27-33. 